\title{
Vasopresores en resucitación cardiopulmonar: la controversia continúa
}

\author{
JUAN JAVIER BOLAÑOS-VERGARAY'1 MARÍA BOVÉ ÁLVAREZ², \\ NUR ABDULKADER AL-MAHMOUD ${ }^{1}$, CHRISTIAN JAVIER BRAVO OBADÍA ${ }^{1}$, MARÍA LEMA TOMÉ ${ }^{1}$
}

Servicio de Anestesiología y Reanimación. Hospital General Universitario Gregorio Marañón. Madrid - España.

Servicio de Oftalmología. Hospital General Universitario Gregorio Marañón. Madrid - España.

\begin{abstract}
The Advanced Cardiac Life Support proposes the use of vasopressor drugs cardiopulmonary resuscitation, with the primary purpose of effectively and early restoration of spontaneous circulation. However, the increased return of spontaneous circulation with vasopressors has not improved neurological outcome at hospital discharge. Adrenaline has traditionally been the main tool of the cardiopulmonary resuscitation guidelines despite the lack of conclusive scientific evidence. Therefore other alternatives were considered at experimental level that has have failed to overcome the clinical results of this drug. In contrastto progress on the standardized management of cardiopulmonary resuscitation, the controversy regarding the effectiveness of vasopressor therapy remains open in the last years due to lack of clinical data to support their usefulness.
\end{abstract}

Key words: Cardiopulmonary resuscitation, cardiac arrest, advanced cardiac life support, vasopressors, adrenaline, vasopressin.

\section{RESUMEN}

El soporte vital avanzado propone el uso de vasopresores durante la resucitación cardiopulmonar, con la finalidad primordial de reestablecer de manera precoz y efectiva la circulación espontánea. Sin embargo, el aumento del retorno a la circulación espontánea asociada a los vasopresores no ha demostrado una mejoría en el pronóstico neurológico al alta hospitalaria. La adrenalina, ha sido tradicionalmente la herramienta principal de las guías de resucitación cardiopulmonar pese a la falta de evidencia científica concluyente. Por ello se han planteado otras alternativas a nivel experimental que no han logrado superar los resultados de este fármaco a nivel clínico. En contraste con los avances respecto al manejo estandarizado de la resucitación cardiopulmonar, el debate con respecto a la efectividad de la terapia vasopresora se mantiene abierto en los últimos años dada la falta de datos clínicos que corroboren su real utilidad.

Palabras clave: Resucitación cardiopulmonar, parada cardiorrespiratoria, soporte vital avanzado, vasopresores, adrenalina, vasopresina.

Todos los autores cumplen los requisitos de autoría, declaran no haber tenido ningún tipo de beca o ayuda (técnica o económica) de cualquier institución y niegan tener algún conflicto de intereses.

Correspondencia a:

Juan Javier Bolaños-Vergaray

drjotabolanos@yahoo.com 


\section{Introducción}

A pesar de los avances en resucitación cardiopulmonar (RCP), el paro cardiorrespiratorio (PCR) es una de las principales causas de muerte a nivel mundial. En USA y Canadá ${ }^{1}$ aproximadamente 350.000 personas al año (de las cuales la mitad ocurren en el hospital), sufren un PCR y reciben RCP (este dato no incluye los PCR que no han recibido RCP). En Europa la incidencia anual de PCR fuera del hospital es de 38 por 100.000 habitantes $^{2}$. La supervivencia al alta hospitalaria de PCR acontecidas fuera del hospital varía de $10,7 \%$ en Europa versus $8,4 \%$ en Norteamérica para todos los ritmos, y se incrementa si presenta fibrilación ventricular $(\mathrm{FV})$ al $21,2 \%$ y $22 \%$, respectivamente 3 .

El principal determinante de la supervivencia y pronóstico neurológico es el ritmo cardiaco inicial del paciente. Generalmente es la FV en $25-30 \%$ de casos, pero si se capta el ritmo cardiaco de manera precoz la FV aumenta a 59-65\%. Muchos de los que presentan FV o taquicardia ventricular (TV) al momento de la PCR acaban derivando en asistolia debido a la demora en su atención ${ }^{3}$.

A nivel hospitalario, la incidencia de PCR es de $1-5$ casos por 1.000 pacientes hospitalizados ${ }^{4}$. La mayor incidencia se correlaciona con el universo de pacientes enfermos en dicho ámbito, siendo la supervivencia al alta de $17,6 \%$ para todos los ritmos. Esta mejora en la supervivencia se entiende por la rápida disponibilidad de medios para $\mathrm{RCP}^{4}$.

Aproximadamente $25 \%$ de los pacientes que sobreviven a un PCR fuera del hospital necesitan tratamiento farmacológico para el retorno a la circulación espontánea $(\mathrm{RCE})^{5}$. El uso de vasopresores durante la RCP tiene como objetivo fundamental favorecer el RCE por medio de un aumento de la vasoconstricción que asegure una adecuada perfusión coronaria y cerebral. La liberación insuficiente de sustancias adrenérgicas durante la PCR es otra razón que justifica su uso. Los objetivos de la presente revisión son conocer la fisiopatología de PCR, la evidencia experimental y clínica de los vasopresores durante la RCP, las diferencias entre estudios experimentales y clínicos, entre distintos ensayos clínicos y conocer las propiedades de un vasopresor ideal.

\section{Fisiopatología de la PCR}

La supervivencia del PCR depende de una secuencia organizada de maniobras terapéuticas, teniendo en cuenta principalmente el tiempo que trascurre desde el inicio del PCR al comienzo de la RCP. En tal sentido, el modelo sobre la secuencia temporal de fases de la resucitación (eléctrica, circulatoria y metabólica), basado en los cambios fisiológicos durante la misma, guarda relación con la prioridad que cada «cambio» tiene con respecto a la aplicación de las maniobras de $\mathrm{RCP}^{6}$.

\section{Fase eléctrica}

Durante los 4 primeros minutos de la RCP las células miocárdicas están llenas de ATP lo cual hace que en esta fase la desfibrilación sea la maniobra más efectiva ${ }^{7}$. La caída progresiva de la supervivencia a corto y largo plazo se correlaciona con el tiempo que demora el uso de la desfibrilación y se corrobora con dos hechos clínicos ${ }^{6,7}$. El primero es la elevada supervivencia (hasta 95\%) por el uso de desfibriladores automáticos implantables durante los primeros 15-20 segundos del inicio de TV/FV. El segundo es la disminución de la supervivencia del $10 \%$ por cada minuto que pasa antes del uso de la desfibrilación. Estudios clínicos con uso de desfibriladores automáticos externos en manos expertas presentaron una supervivencia mayor del $50 \%$ con un tiempo promedio de desfibrilación de 5,5 $\mathrm{min}^{8}$.

\section{Fase circulatoria}

El beneficio de la desfibrilación después de los primeros 4 min disminuye por la depleción de ATP en los miocitos cardiacos que a su vez reduce la contracción efectiva del miocardio luego de la desfibrilación. Basados en este hecho, se efectuó 90 segundos de RCP en humanos antes de la desfibrilación ${ }^{9} \sin$ considerar el tiempo de arribo del personal de RCP. Se encontró un aumento de supervivencia cuando la RCP se realizaba antes de la desfibrilación. Un ensayo clínico ${ }^{10}$ de 200 pacientes con FV fuera del hospital los dividió en dos grupos, uno recibió RCP antes de la desfibrilación y un grupo control manejo estándar con desfibrilación inicial. La supervivencia fue del $22 \%$ y de $15 \%$ respectivamente. Si el tiempo de respuesta era menor de $5 \mathrm{~min}$, no se encontraron diferencias significativas de supervivencia, pero 
hubo una tendencia a favor del grupo control ( $29 \%$ versus $23 \%$ ).

\section{Fase metabólica}

Un PCR que dura más de 10 min disminuye drásticamente la efectividad de la RCP y la desfibrilación. La adrenalina incrementa el flujo cerebral y miocárdico, sin embargo, altas dosis disminuyen el flujo renal e intestinal con el consiguiente daño en dichos órganos. Esta es la fase que plantea la mayor cantidad de interrogantes. No obstante, la hipotermia es la mayor innovación para su comprensión. Si la superficie corporal se mantenía a $32-34^{\circ} \mathrm{C}$ durante $24-48 \mathrm{~h}$ se demostró un aumento en la supervivencia a largo plazo con resultados estadísticamente significativos (1 paciente sobrevivía por cada 7 sometidos a hipotermia $)^{11}$. Se desconoce cuál es la clave de los efectos metabólicos para el daño isquémico generalizado, si son toxinas producidas que pueden ser antagonizadas o los mecanismos que podrían utilizarse para tolerar la isquemia además de la hipotermia ${ }^{12}$.

\section{Lesión por reperfusión}

La reperfusión precoz ${ }^{13}$ fue el tratamiento de la isquemia hasta que se descubrió que producía daño conjunta e independientemente de la isquemia. La lesión por reperfusión es la disfunción miocárdica, vascular, metabólica o electrofisiológica luego de restaurar el flujo sanguíneo en un tejido isquémico. Sus manifestaciones incluyen arritmias de reperfusión, daño endotelial, enlentecimiento miocardio, necrosis, daño por radicales libres, hemorragia y respuesta inflamatoria sistémica. Se plantea que podría ser la cuarta fase del modelo de 3 fases de el PCR.

\section{Adrenalina}

Durante la RCP se recomienda la administración de 1 miligramo $(\mathrm{mg})$ de adrenalina ${ }^{1,2}$, independientemente del ritmo de PCR, cada 3-5 min hasta conseguir la RCE.

\section{Efectos fisiológicos}

Los efectos benéficos en RCP son esencialmente $\alpha$ adrenérgicos por la vasoconstricción sistémica, lo cual aumenta la presión de perfusión cerebral (PPC) y coronaria (PPCo) $)^{14}$. La PPCo es el mayor determinante de flujo coronario y se define como la diferencia entre la presión aórtica y la presión de la aurícula derecha durante la fase de relajación. Si la RCP no es capaz de generar una $\mathrm{PPC}_{0}$ superior a $15-20 \mathrm{~mm} \mathrm{Hg}$ (reflejado en una mejora del $\mathrm{CO}_{2}$ espirado) resulta improbable el $\mathrm{RCE}^{15}$. Los efectos $\beta$ inotropo y cronotropo positivos desencadenan efectos nocivos como aumentar el consumo de oxígeno miocárdico, arritmias ventriculares (sobre todo si el tejido cardíaco está acidótico), hipoxemia transitoria, fallo cardíaco y disfunción miocárdica post $\mathrm{RCP}^{16}$. A pesar de los efectos $\beta$, la mejora a corto plazo de la supervivencia es el mayor argumento para continuar su utilización.

\section{Adrenalina en estudios experimentales}

Los modelos animales han corroborado los efectos dañinos $\beta$ y estudios recientes han reportado una disminución del flujo micro circulatorio cerebral ${ }^{17}$ post RCE con adrenalina. Esta hipoperfusión es atribuible al efecto $\alpha 1$, que disminuye la microcirculación de los órganos vitales a nivel celular, reduce la concentración de oxígeno cerebral con un aumento de $\mathrm{pCO}_{2}$ (presión parcial de $\mathrm{CO}_{2}$ ) y un mínimo aumento del flujo carotídeo. Estudios experimentales en los que se ha mejorado la hipoperfusión microvascular, ocasionada por la adrenalina, mediante el uso de nitroprusiato o nitroglicerina sugieren que en un futuro la investigación podría estar dirigida a mejorar el flujo sanguíneo microvascular en lugar de maximizar la presión en las grandes arterias.

\section{Adrenalina datos clínicos}

\section{- Adrenalina versus placebo}

\section{Incremento $R C E$}

Una revisión ${ }^{18}$ evaluó 1.203 pacientes con PCR por FV que recibieron o no adrenalina. Se obtuvo una alta tasa de RCE y de supervivencia al ingreso hospitalario en los que se utilizó adrenalina después del tercer intento de desfibrilación sin encontrar beneficio en la supervivencia al alta hospitalaria. En Australia un estudio doble ciego aleatorizado comparó adrenalina con placebo en PCR fuera del hospital. La adrenalina también incrementó el RCE, pero sin diferencias significativas al alta hospitalaria. Uno de los principa- 
les sesgos de este estudio es el tamaño muestral, porque se planteó incluir 5.000 pacientes de 5 servicios de ambulancia, pero 4 decidieron no participar, por lo que finalmente se incluyeron 273 pacientes en el grupo de la adrenalina y 262 del grupo placebo lo cual disminuyó la potencia del estudio ${ }^{20}$.

En Oslo ${ }^{21}$ se realizó un ensayo retrospectivo aleatorizado con dos grupos en PCR fuera del hospital: canalización intravenosa (IV) y administración farmacológica durante la RCP versus no canalización IV o administración de fármacos hasta el RCE. Incluyeron 851 pacientes (418 IV y 433 no IV). Se encontró un retorno del pulso $(40 \%$ en IV y $25 \%$ no IV) y mayor ingreso a cuidados intensivos ( $30 \%$ en IV y $20 \%$ no IV), pero sin diferencias en recuperación neurológica, supervivencia al año o al alta hospitalaria. Las mejoras en RCE e ingreso hospitalario ocurrieron en ritmos iniciales no desfibrilables, sin diferencias encontradas para los ritmos inicialmente desfibrilables. Dicho ascenso de ingresos hospitalarios podría relacionarse con un manejo potencialmente mejor y un aumento en la supervivencia a largo plazo. Sin embargo, gran parte de estos pacientes muere, además de la carga asistencial y el incremento del uso de recursos en las unidades de cuidados intensivos. El mayor aporte de este estudio fue la hipotermia post RCP. Un análisis post hoc ${ }^{22}$ del estudio de Oslo comparó los resultados entre los pacientes que recibieron $(\mathrm{n}=367)$ o no $(\mathrm{n}=481)$ adrenalina. El grupo adrenalina presentó una mejora de supervivencia a corto plazo con disminución de supervivencia al alta o al año del episodio y un mal pronóstico neurológico.

Otro estudio ${ }^{23}$ comparó el antes versus el después del inicio del uso de adrenalina y encontró un aumento de RCE (14,6 y 10,9\% respectivamente), sin diferencias de supervivencia al alta hospitalaria.

Actualmente, la base de datos más grande sobre el uso de adrenalina en RCP, es el estudio observacional de Japón con 417.188 pacientes. Los objetivos eran medir RCE antes de llegar al hospital, supervivencia al mes, supervivencia con buena o moderada función cerebral y la supervivencia según la discapacidad neurológica. Concluyeron que la adrenalina está asociada con disminución de la supervivencia y mal pronóstico neurológico un mes después del evento, a pe- sar del beneficio a corto plazo determinado por el incremento de RCE antes del ingreso hospitalario $^{24}$.

Los estudios anteriormente citados tienen en común el incremento de RCE, pero a pesar de ello no presentan una mejoría en la supervivencia al alta o pronóstico neurológico. Estos resultados plantean nuevamente el debate del beneficio de la adrenalina en RCP, sin embargo, la comunidad científica se ha mostrado reticente a modificar su indicación por la dificultad que conlleva realizar un ensayo clínico aleatorizado doble ciego durante una situación vital además de incrementar la investigación de nuevos fármacos.

\section{Sin incremento $R C E$}

Uno de los pocos estudios que no encontró diferencias en RCE, supervivencia al ingreso o al alta hospitalaria; fue el realizado en Singapur ${ }^{19}$, que analizó la supervivencia de 1.206 pacientes antes y después de inicio del uso de la adrenalina en PCR fuera del hospital.

\section{- Dosis bajas versus altas de adrenalina}

La dosis estándar de $1 \mathrm{mg}$ utilizada en los algoritmos de RCP proviene de estudios realizados en perros. Por ello se han realizado estudios en búsqueda de la dosis "ideal" en humanos. Se han comparado dosis bajas (bolos de $1 \mathrm{mg}$ con $4 \mathrm{mg}$ de dosis máxima) y dosis altas $(5,10$ y $15 \mathrm{mg}$ en dosis sucesivas, $30 \mathrm{mg}$ como máximo $)^{25}, 4$ $\mathrm{mg}^{26}$ ó $15 \mathrm{mg}^{27}$ como dosis total y más de $15 \mathrm{mg}^{28}$ como dosis total. Ninguno demostró una mejora de supervivencia al ingreso, al alta hospitalaria y pronóstico neurológico por lo que la evidencia científica continúa a favor de la dosis estándar ${ }^{29}$. Un meta análisis ${ }^{30}$ comparó dosis estándar y dosis altas (5-15 mg) y demostró mejoría de RCE con dosis altas sin aumento de supervivencia a largo plazo en ninguno de los grupos. Resulta interesante saber que los diversos estudios que tenían como objetivo determinar la dosis "ideal" de adrenalina en humanos son de hace más de 15 años, lo cual corrobora la duda científica acerca de la real utilidad de esta droga en RCP. En tal sentido, la recomendación de la adrenalina como fármaco de elección para la RCP durante más de 40 años, no se sustenta en evidencia científica que haya comprobado una mejora en la supervivencia a largo plazo. 


\section{Vasopresina}

Durante la RCP se recomienda la administración de 40 unidades internacionales (UI) de vasopresina $^{1,2}$, independientemente del ritmo de PCR, como reemplazo a la primera o segunda dosis de adrenalina.

\section{Efectos fisiológicos}

Los niveles altos de vasopresina de los pacientes que sobrevivían a una PCR, fue clave para plantearse su uso en RCP. Sus ventajas son la mejora del flujo sanguíneo cerebral y coronario, ausencia de efectos secundarios $\beta$ coronarios, efecto vasoconstrictor mantenido durante la hipoxia, tiempo de vida mayor (10-20 $\mathrm{min})$, no afectación de sus receptores por la acidosis y menor riesgo de disfunción miocárdica post $\mathrm{RCP}^{31}$. A dosis altas no produce agregación plaquetaria en comparación de la adrenalina. Sin embargo, se desconoce sus efectos procoagulantes durante la $\mathrm{PCR}^{15}$, porque induce actividad coagulante en individuos sanos, hemofílicos, con enfermedad renal, hepática y después de cirugía cardiaca. Uno de sus principales efectos deletéreos es la vasoconstricción continua que puede originar un aumento en la resistencia sistémica en el período post $\mathrm{RCP}^{15}$.

\section{Vasopresina estudios experimentales}

Comparado con adrenalina ha logrado aumentar la supervivencia con una mejoría neurológica $^{32}$. Otro estudio de vasopresina versus vasopresina-adrenalina, demostró mejoría del flujo sanguíneo cerebral durante la $\mathrm{RCP}^{33}$. La combinación vasopresina-adrenalina versus adrenalina incrementó la presión diastólica aórtica, PPCo y la $\mathrm{RCE}^{34}$.

\section{Vasopresina datos clínicos}

\section{- Vasopresina (sola o en combinación con adrenalina) versus adrenalina}

A diferencia de los estudios experimentales, los ensayos clínicos no han demostrado un beneficio con respecto a la adrenalina. Una de las razones que se plantean es que los receptores en cerdos (lisina vasopresina) y en humanos (arginina vasopresina) son diferentes, lo cual determinaría respuestas hemodinámicas diferentes.

\section{Incremento RCE}

Un estudio prospectivo ${ }^{39}$ de 109 pacientes, comparó la administración de 40 UI de vasopresina seguido de 3 dosis de $1 \mathrm{mg}$ de adrenalina versus $40 \mathrm{UI}$ de vasopresina versus un grupo retrospectivo control con 3 dosis de adrenalina en pacientes con FV/TV sin pulso. La mejora en RCE y supervivencia a las $24 \mathrm{~h}$ del grupo donde se utilizó vasopresina no se correlacionó con un aumento significativo en la supervivencia al alta hospitalaria y pronóstico neurológico entre los grupos. Como se puede apreciar, el incremento inicial del RCE no aseguró la mejoría en otros parámetros importantes a la hora de valorar la RCP.

\section{Sin incremento $R C E$}

En Canadá ${ }^{35}$ se comparó vasopresina versus adrenalina en 200 pacientes en PCR hospitalaria y no encontraron diferencias de supervivencia al alta hospitalaria, pronóstico neurológico o supervivencia a la hora del evento.

Un estudio multicéntrico ${ }^{36}$ de 1.186 pacientes, los aleatorizó en dos grupos, vasopresina $(\mathrm{n}=589)$ y adrenalina $(\mathrm{n}=597)$ con PCR fuera del hospital. No encontraron diferencias en la RCE ( $24 \%$ y $28 \%$ respectivamente), alta hospitalaria $(9,9 \%$ en ambos grupos) y pronóstico neurológico. Un análisis post hoc determinó una mejora en la supervivencia con vasopresina en pacientes con asistolia asociada a un mal pronóstico neurológico. Con los resultados del análisis post hoc se realizaron dos estudios aleatorizados con un total de 4.300 pacientes que compararon vasopresina-adrenalina con adrenalina. No encontraron mejoría en la RCE, supervivencia a largo plazo o recuperación neurológica para la combinación. Estos resultados revelan que la vasopresina aún no demuestra una mejoría del pronóstico en comparación con la adrenalina ${ }^{37,38}$. El tiempo de administración del fármaco (22 min para vasopresina), fue probablemente la causa por la que no se encontraron ritmos desfibrilables al inicio de la $\mathrm{RCP}^{38}$. Otras limitaciones a la hora de comparar estos estudios son los diferentes tamaños muestrales $\left(325^{37}\right.$ y $\left.3.296^{38}\right)$, y las dosis. Uno utilizó dosis crecientes ${ }^{38}$ en los usos sucesivos y el otro repetía la misma dosis ${ }^{37}$.

Otro ensayo clínico japonés ${ }^{40}$ de 366 pacientes, analizó la efectividad de un máximo de 4 dosis de 40 UI de vasopresina o de $1 \mathrm{mg}$ de 
adrenalina como único vasopresor en PCR fuera del hospital. Se excluyó a los pacientes que recibieron cualquier vasopresor antes de llegar al hospital. No encontraron diferencias en RCE, supervivencia a las $24 \mathrm{~h}$ o al alta hospitalaria. El tiempo en el que se administró el vasopresor (más de 30 min en ambos grupos) y la falta de datos sobre el pronóstico neurológico son sus principales limitaciones.

Un meta análisis ${ }^{41}$ de 1.519 pacientes, comparó vasopresina versus adrenalina y no encontró diferencias en tasa de RCE, supervivencia al alta hospitalaria o supervivencia con una buena recuperación neurológica. Otro metaanálisis ${ }^{42}$ reciente de 4.475 pacientes comparó vasopresina con/ sin adrenalina y adrenalina. No encontró mejoría en RCE, supervivencia a largo plazo y pronóstico neurológico. Se encontró un incremento de supervivencia a largo plazo (sin analizar el pronóstico neurológico), en pacientes con asistolia y uso de vasopresina.

Según los resultados expuestos de los estudios, se puede concluir que no existen ventajas de la vasopresina sobre la adrenalina en PCR por lo que no se debería recomendar en los protocolos de soporte avanzado, hasta no disponer de más ensayos clínicos sobre la superioridad de la vasopresina respecto a la adrenalina.

\section{- Combinación adrenalina-vasopresina}

Un estudio retrospectivo ${ }^{43}$ comparó adrenalina $(\mathrm{n}=231)$ y combinación adrenalina-vasopresina $(n=37)$ en PCR extra hospitalario. El RCE mejoró con la combinación cuando la asistolia era el ritmo inicial pero sin encontrar diferencias significativas.

La mayor disponibilidad de la evidencia científica actual sobre fármacos en RCP se ha centrado en comparar la vasopresina con la adrenalina, sin corroborar que la estimulación simultánea o no de los receptores de catecolaminas y vasopresina mejore la perfusión de órganos vitales durante la RCP y disminuya los efectos secundarios encontrados en animales.

\section{Otros vasopresores versus adrenalina}

Alternativas como Metoxamina ${ }^{44}$, Norepinefrina $^{45}$, Fenilefrina ${ }^{46}$ no han demostrado beneficio sobre la adrenalina en supervivencia, RCE o pronóstico neurológico.
Vasopresores alternativos antes de terlipresina

Es un análogo sintético de la vasopresina. Se planteó en RCP por el tiempo de acción más prolongado que la vasopresina y por el éxito como vasopresor de segunda línea en niños con shock séptico refractario, por ello los estudios son principalmente en población pediátrica. En una serie de $7 \operatorname{casos}^{47}$ de pacientes pediátricos, que presentaron 8 episodios de PCR refractarios al manejo convencional, se administró terlipresina, con mejoría de RCE en 6 de los 8 episodios, siendo dados de alta 4 pacientes con buen pronóstico neurológico. Se proyecta como opción a la vasopresina pero la evidencia científica aún es baja.

\section{Endotelina $1^{48}$}

Su relación con la RCP no sólo se debe al descubrimiento del aumento de sus niveles en los que sobrevivieron a una PCR, sino a su mecanismo de acción (vasoconstricción, efecto cronotropo e inotropo positivo), además de observar una relación positiva entre la endotelina $1 \mathrm{y}$ el pronóstico. La investigación está centrada en modelos experimentales.

Los vasopresores alternativos, solos o en combinación, deberían demostrar su eficacia al optimizar la RCP, esto es, reduciendo el tiempo en el que aparece la RCE y manteniendo dichos resultados positivos a largo plazo demostrables por la supervivencia o el pronóstico neurológico al alta.

\section{Evidencia clínica}

La Tabla 1 muestra las diferencias entre estudios experimentales y clínicos ${ }^{13-15,49,50}$.

La Tabla 2 presenta las diferencias entre datos clínicos ${ }^{1,2,14,15}$.

\section{Propiedades ideales de un vasopresor para RCP}

Se exponen en la Tabla $3^{13,14,49}$.

\section{Conclusiones}

- El éxito de una intervención durante la RCP, como es el uso de vasopresores, debe de ser valorada de acuerdo a la recuperación neuro- 
Tabla 1. Diferencias entre estudios experimentales y datos clínicos en RCP

- Las condiciones ideales de los modelos experimentales que disponen de toda la logística en el momento que la requieren

- Los modelos experimentales son por lo general animales sanos sin enfermedad coronaria

- La diferente fisiopatología entre animales y humanos de PCR

- Gran parte de los modelos animales presentan PCR por una taquiarritmia mientras que la principal causa de PCR en humanos es la enfermedad coronaria

- La RCP en humanos depende del entrenamiento del reanimador que tiene una tendencia a ser pobre (incluso en personal experto), la cual es uniforme en estudios experimentales

- El tiempo de administración del fármaco para ser efectivo. A nivel experimental presentan tiempos precoces de administración de aproximadamente 9,5 minutos (durante la fase circulatoria), a comparación de los datos clínicos de aproximadamente 19,4 minutos (fase metabólica)

- Los modelos animales no ofrecen información acerca del pronóstico neurológico que es el principal objetivo de interés a extrapolar en los pacientes

\section{Tabla 2. Diferencias entre datos clínicos en RCP}

- La dificultad de elaborar un protocolo de investigación para RCP primordialmente por su aplicabilidad en el momento mismo de tomar la decisión de seguir o no el protocolo

- El tamaño muestral inicial difiere del tamaño final por la falta de facilidades logísticas, negativa del médico o centros a reclutar pacientes, lo cual resta potencia al estudio para detectar diferencias

- Debilidades del protocolo como no ser ciego para el médico o no incluir un grupo control

- Por razones éticas muchos protocolos que inicialmente son ciegos incluyen la opción de administrar adrenalina si el fármaco a prueba no produce el efecto deseado

- Los tiempos de inicio de PCR por lo general son aproximados

- Muchos ensayos no documentan el tiempo de administración del fármaco, sea por la dificultad que una situación de emergencia implica o por intereses de los investigadores al momento de mostrar la conveniencia de sus resultados (sesgo de publicación)

- La interpretación y comparación de resultados se dificulta por la variedad de objetivos. Desde objetivos simples que sólo evalúan el tiempo de RCE, y los complejos que analizan supervivencia al mes, al alta y el pronóstico neurológico al alta

Tabla 3. Propiedades de un vasopresor ideal en RCP

- Incrementar la perfusión cerebral y coronaria durante la RCP, sin generar vasoconstricción a dichos niveles (aunque la vasodilatación coronaria podría ser beneficial)

- No incrementar el consumo de oxígeno miocárdico

- Tiempo de vida media plasmático largo que permita una dosificación infrecuente durante la RCP

- No interferir a nivel plaquetario o de la coagulación

- Proteger contra los efectos dañinos de los niveles altos de las catecolaminas endógenas

- No presentar metabolitos con propiedades tóxicas o que neutralicen los efectos benéficos

lógica del paciente. La relevancia clínica de este evento debe de tomarse en cuenta para decidir la inclusión de nuevos fármacos en las guías de RCP.

- A pesar de la falta de evidencia clínica las recomendaciones en RCP han mantenido el uso de adrenalina como uno de sus pilares.
- Los múltiples mecanismos de PCR hacen difícil conceptualizar la idea que solamente un fármaco (adrenalina), pueda ser el adecuado para todas las causas de PCR (lo cual también se debe a la falta de descubrimiento de fármacos alternativos). Este hecho se podría traducir en el desarrollo de una combinación 
de fármacos, que podrían ser útiles por la suma de sus efectos teóricos, pero que se dificulta por las múltiples dosis de prueba que ocasionarían efectos secundarios no conocidos y por el desconocimiento del momento adecuado de administración de los actuales vasopresores durante la RCP que puedan servir de guía para las futuras investigaciones.

- A pesar de todos los esfuerzos científicos por incrementar el conocimiento sobre los fármacos vasopresores y dado que actualmente ningún vasopresor ha demostrado mejorar la supervivencia al alta hospitalaria después de una PCR, la piedra angular de la RCP son las compresiones cardiacas y la desfibrilación precoz que no deben interrumpirse en lugar de conseguir un acceso venoso, administrar un fármaco o el manejo avanzado de la vía aérea.

\section{Referencias}

1. Travers AH, Rea TD, Bobrow BJ, Edelson DP, Berg RA, Sayre MR et al. Part 4: CPR overview: 2010 American Heart Association Guidelines for Cardiopulmonary Resuscitation and Emergency Cardiovascular Care. Circulation 2010 Nov;122(18 Suppl 3):S676-S684.

2. Nolan JP, Soar J, Zideman DA, Biarent D, Bossaert LL, Deakin $\mathrm{C}$ et al. ERC Guidelines Writing Group. European Resuscitation Council Guidelines for Resuscitation 2010 Section 1. Executive summary. Resuscitation 2010 Oct;81(10):1219-1276.

3. Atwood C, Eisenberg MS, Herlitz J, Rea TD. Incidence of EMS-treated out-of-hospital cardiac arrest in Europe. Resuscitation 2005 Oct;67(1):75-80.

4. Meaney PA, Nadkarni VM, Kern KB, Indik JH, Halperin HR, Berg RA. Rhythms and outcomes of adult in-hospital cardiac arrest. Crit Care Med 2010 Jan;38(1):101-108.

5. Bunch TJ, White RD, Gersh BJ, Meverden RA, Hodge DO, Ballman KV et al. Long-term outcomes of out-of-hospital cardiac arrest after successful early defibrillation. N Engl J Med 2003 Jun;348(26):2626-2633.

6. Weisfeldt ML, Becker LB. Resuscitation after cardiac arrest: a 3-phase time-sensitive model. JAMA 2002 Dec;288(23):30353038.

7. Becker LB, Weisfeldt ML, Weil MH, Budinger T, Carrico J, Kern K et al. The PULSE initiative: scientific priorities and strategic planning for resuscitation research and life saving therapies. Circulation 2002 May;105(21):2562-2570.

8. Caffrey SL, Willoughby PJ, Pepe PE, Becker LB. Public use of automated external defibrillators. N Engl J Med 2002 Oct;347(16):1242-1247.

9. Cobb LA, Fahrenbruch CE, Walsh TR, Copass MK, Olsufka $\mathrm{M}$, Breskin $\mathrm{M}$ et al. Influence of cardiopulmonary resuscitation prior to defibrillation in patients with out-of-hospital ventricular fibrillation. JAMA 1999 Apr;281(13):1182-1188.

10. Wik L, Hansen TB, Fylling F, Steen T, Vaagenes P, Auestad BH et al. Delaying defibrillation to give basic cardiopulmonary resuscitation to patients with out-ofhospital ventricular fibrillation: a randomized trial. JAMA 2003 Mar;289(11):1389-1395.

11. Hypothermia after Cardiac Arrest Study Group. Mild therapeutic hypothermia to improve the neurologic outcome after cardiac arrest. N Engl J Med 2002 Feb;346(8):549-556.

12. Bernard SA, Gray TW, Buist
MD, Jones BM, Silvester W, Gutteridge $\mathrm{G}$ et al. Treatment of comatose survivors of out-ofhospital cardiac arrest with induced hypothermia. N Engl J Med 2002 Feb;346(8):557-563.

13. Penson PE, Ford WR, Broadley KJ. Vasopressors for cardiopulmonary resuscitation. Does pharmacological evidence support clinical practice? Pharmacol Ther 2007 Jul;115(1):37-55.

14. Callaway CW. Questioning the use of epinephrine to treat cardiac arrest. JAMA 2012 Mar;307(11):1198-1200.

15. Zhong JQ, Dorian P. Epinephrine and vasopressin during cardiopulmonary resuscitation. Resuscitation 2005 Sep;66(3):263-269.

16. Klouche K, Weil MH, Tang W, Povoas H, Kamohara T, Bisera J. A selective alpha(2)-adrenergic agonist for cardiac resuscitation. J Lab Clin Med 2002 Jul;140(1):27-34.

17. Ristagno G, Tang W, Huang L, Fymat A, Chang YT, Sun S et al. Epinephrine reduces cerebral perfusion during cardiopulmonary resuscitation. Crit Care Med 2009 Apr;37(4):1408-1415.

18. Herlitz J, Ekström L, Wennerblom B, Axelsson A, Bång A, Holmberg S. Adrenaline in out-of-hospital ventricular fibrillation. Does it make any difference? Resuscitation 1995 Jun;29(3):195-201. 
19. Ong ME, Tan EH, Ng FS, Panchalingham A, Lim SH, Manning PG et al. Cardiac Arrest and Resuscitation Epidemiology Study Group. Survival outcomes with the introduction of intravenous epinephrine in the management of out-of-hospital cardiac arrest. Ann Emerg Med 2007 Dec;50(6):635-642.

20. Jacobs IG, Finn JC, Jelinek GA, Oxer HF, Thompson PL. Effect of adrenaline on survival in out-of-hospital cardiac arrest: A randomised double-blind placebo-controlled trial. Resuscitation 2011 Sep;82(9):1138-1143.

21. Olasveengen TM, Sunde K, Brunborg C, Thowsen J, Steen PA, Wik L. Intravenous drug administration during outof-hospital cardiac arrest: a randomized trial. JAMA 2009 Nov;302(20):2222-2229.

22. Olasveengen TM, Wik L, Sunde $\mathrm{K}$, Steen PA. Outcome when adrenaline (epinephrine) was actually given $v s$ not given - post hoc analysis of a randomized clinical trial. Resuscitation 2012 Mar;83(3):327-332.

23. Stiell IG, Wells GA, Field B, Spaite DW, Nesbitt LP, De Maio VJ et al. Ontario Prehospital Advanced Life Support Study Group. Advanced cardiac life support in out-of-hospital cardiac arrest. N Engl J Med 2004 Aug;351(7):647-656.

24. Hagihara A, Hasegawa M, Abe T, Nagata T, Wakata Y, Miyazaki S. Prehospital epinephrine use and survival among patients with out-of-hospital cardiac arrest. JAMA 2012 Mar;307(11):11611168.

25. Carvolth RD, Hamilton AJ. Comparison of high-dose epinephrine versus standard-dose epinephrine in adult cardiac arrest in the prehospital setting.
Prehosp Disaster Med 1996 JulSep;11(3):219-222.

26. Behringer W, Kittler H, Sterz F, Domanovits H, Schoerkhuber

W, Holzer $\mathrm{M}$ et al. Cumulative epinephrine dose during cardiopulmonary resuscitation and neurologic outcome. Ann Intern Med 1998 Sep;129(6):450-456.

27. Gueugniaud PY, Mols P, Goldstein P, Pham E, Dubien PY, Deweerdt $\mathrm{C}$ et al. European Epinephrine Study Group. A comparison of repeated high doses and repeated standard doses of epinephrine for cardiac arrest outside the hospital. N Engl J Med 1998 Nov;339(22):1595-1601.

28. Rivers EP, Wortsman J, Rady MY, Blake HC, McGeorge FT, Buderer NM. The effect of the total cumulative epinephrine dose administered during human CPR on hemodynamic, oxygen transport, and utilization variables in the postresuscitation period. Chest 1994 Nov;106(5):1499-1507.

29. Babbs CF, Berg RA, Kette F, Kloeck WG, Lindner KH, Lurie $\mathrm{KG}$ et al. American Heart Association; International Liaison Committee on Resuscitation. Use of pressors in the treatment of cardiac arrest. Ann Emerg Med 2001 Apr;37(4 Suppl):S152-S162.

30. Vandycke C, Martens P. High dose versus standard dose epinephrine in cardiac arrest - a metaanalysis. Resuscitation 2000 Aug;45(3):161-166.

31. Treschan TA, Peters J. The vasopressin system: physiology and clinical strategies. Anesthesiology 2006 Sep;105(3):599-612.

32. Wenzel V, Lindner KH, Krismer AC, Voelckel WG, Schocke MF, Hund W et al. Survival with full neurologic recovery and no cerebral pathology after prolonged cardiopulmonary resuscitation with vasopressin in pigs. J Am Coll Cardiol 2000 Feb;35(2):527-533.

33. Voelckel WG, Lurie KG, McKnite S, Zielinski T, Lindstrom $\mathrm{P}$, Peterson $\mathrm{C}$ et al. Effects of epinephrine and vasopressin in a piglet model of prolonged ventricular fibrillation and cardiopulmonary resuscitation. Crit Care Med 2002 May;30(5):957-962.

34. Stroumpoulis K, Xanthos T, Rokas G, Kitsou V, Papadimitriou D, Serpetinis I et al. Vasopressin and epinephrine in the treatment of cardiac arrest: an experimental study. Crit Care 2008;12(2):R40.

35. Stiell IG, Hébert PC, Wells GA, Vandemheen KL, Tang AS, Higginson LA et al. Vasopressin versus epinephrine for inhospital cardiac arrest: a randomised controlled trial. Lancet 2001 Jul;358(9276):105-109.

36. Wenzel V, Krismer AC, Arntz HR, Sitter H, Stadlbauer KH, Lindner KH; European Resuscitation Council Vasopressor during Cardiopulmonary Resuscitation Study Group. A comparison of vasopressin and epinephrine for out-of-hospital cardiopulmonary resuscitation. N Engl J Med 2004 Jan;350(2):105-113.

37. Callaway CW, Hostler D, Doshi AA, Pinchalk M, Roth RN, Lubin J et al. Usefulness of vasopressin administered with epinephrine during out-of-hospital cardiac arrest. Am J Cardiol 2006 Nov;98(10):1316-1321.

38. Gueugniaud PY, David JS, Chanzy E, Hubert H, Dubien PY, Mauriaucourt P et al. Vasopressin and epinephrine vs epinephrine alone in cardiopulmonary resuscitation. N Engl J Med 2008 Jul;359(1):21-30.

39. Grmec S, Mally S. Vasopressin 
improves outcome in outof-hospital cardiopulmonary resuscitation of ventricular fibrillation and pulseless ventricular tachycardia: a observational cohort study. Crit Care 2006 Feb;10(1):R13.

40. Mukoyama T, Kinoshita K, Nagao K, Tanjoh K. Reduced effectiveness of vasopressin in repeated doses for patients undergoing prolonged cardiopulmonary resuscitation. Resuscitation 2009 Jul;80(7):755-761.

41. Aung K, Htay T. Vasopressin for cardiac arrest: a systematic review and meta-analysis. Arch Intern Med 2005 Jan;165(1):1724.

42. Mentzelopoulos SD, Zakynthinos SG, Siempos I, Malachias S, Ulmer H, Wenzel V. Vasopressin for cardiac arrest: meta-analysis of randomized controlled trials. Resuscitation 2012 Jan;83(1):3239.

43. Guyette FX, Guimond GE, Host- ler D, Callaway CW. Vasopressin administered with epinephrine is associated with a return of a pulse in out-of-hospital cardiac arrest. Resuscitation 2004 Dec;63(3):277-282.

44. Patrick WD, Freedman J, McEwen T, Light RB, Ludwig L, Roberts D. A randomized, double-blind comparison of methoxamine and epinephrine in human cardiopulmonary arrest. Am J Respir Crit Care Med 1995 Aug;152(2):519-523.

45. Callaham M, Madsen CD, Barton CW, Saunders CE, Pointer $\mathrm{J}$. A randomized clinical trial of high-dose epinephrine and norepinephrine $v s$ standarddose epinephrine in prehospital cardiac arrest. JAMA 1992 Nov;268(19):2667-2672.

46. Silfvast T, Saarnivaara L, Kinnunen A, Erosuo J, Nick L, Pesonen $\mathrm{P}$ et al. Comparison of adrenaline and phenylephrine in out-of-hospital cardiopulmonary resuscitation. A double-blind study. Acta Anaesthesiol Scand 1985 Aug;29(6):610-613.

47. Matok I, Vardi A, Augarten A, Efrati O, Leibovitch L, Rubinshtein $\mathrm{M}$ et al. Beneficial effects of terlipressin in prolonged pediatric cardiopulmonary resuscitation: a case series. Crit Care Med 2007 Apr;35(4):11611164.

48. Shah AP, Niemann JT, Youngquist S, Heyming T, Rosborough JP. Plasma endothelin-1 level at the onset of ischemic ventricular fibrillation predicts resuscitation outcome. Resuscitation 2009 May;80(5):580-583.

49. Callaway CW. Epinephrine for cardiac arrest. Curr Opin Cardiol 2013 Jan;28(1):36-42.

50. Reynolds JC, Rittenberger JC, Menegazzi JJ. Drug administration in animal studies of cardiac arrest does not reflect human clinical experience. Resuscitation 2007 Jul;74(1):13-26. 